\title{
Corralling Culture as a Concept in LIS Research
}

\author{
Rachel Salzano, Edinburgh Napier University, r.salzano@ napier.ac.uk \\ Hazel Hall, Edinburgh Napier University, h.hall@napier.ac.uk \\ Gemma Webster, Edinburgh Napier University, g.webster@napier.ac.uk
}

83rd Annual Meeting of the Association for Information Science \& Technology | October 2428, 2020. Author(s) retain copyright, but ASIS\&T receives an exclusive publication license.

\begin{abstract}
Individuals' cultural backgrounds influence their use of societal resources, including libraries. A literature search and review was completed on the treatment of culture in library and information science (LIS) in the body of work on information behaviour and use. While much of the literature reviewed cites culture as an important influence, few researchers define culture as a concept, nor do they explore in detail the factors that it comprises. In this body of work culture is primarily used in two ways: (1) to differentiate groups of library users; and (2) to draw attention to questions of integration.
\end{abstract}

\section{Introduction}

Cultural factors impact individuals' behaviours (Kitayama \& Uskul, 2011). In respect of specific populations, it has been identified that cultural factors influence public library use (e.g. Audunson et al., 2011). In preparation for a larger study on the impact of culture on the use of public libraries by new-comer populations such as immigrants and refugees, a literature review was completed. The larger study will investigate which cultural factors influence use of public library resources, particularly in new-comers who may have different perceptions of the resources available. For the purposes of the larger study, drawing on Brady et al. (2018) and Shoham and Rabinovich (2008), 'culture' is understood as the values systems, patterns of behaviours, and accepted norms derived from historical traditions that are passed down to the next generation within a group. The poster to be presented at ASIST2020 explores the treatment of the theme of culture in library and information science (LIS) publications. The approach to identifying relevant literature and the findings of the analysis are outlined below. The outcomes of this analysis will be used to inform the ways the larger study will address the concept of culture.

\section{Methodology}

A literature search was conducted on the ExLibris-hosted catalogue of an academic library, and Google Scholar. The decision to use the ExLibris-hosted catalogue was driven by accessibility, the nature of the project as a scoping exercise, and the ability to access multiple LIS databases (e.g., LISA and LISTA) through a single search. Subject filters were used to narrow down search results. Citation pearling was also deployed to capture material not returned in the initial search results. Relevant materials were then reviewed, thematically mapped, and manually coded. Of the papers accessed, $35^{1}$ were highly relevant to the theme of culture. Keywords used to determine relevance were culture, cultural, multi-cultural, multi-culturalism, and socio-cultural. The presence of such keywords in the title, abstract, or text of a paper led to a deeper reading. Papers were included in the analysis if the concept of culture was discussed as an influential factor of information behaviours or information practices, especially within libraries.

\footnotetext{
${ }^{1}$ The full list will be supplied in a list to supplement the poster. To include this with this submission would have exceeded the word count.
} 


\section{Results}

Multiple researchers claim that culture influences information behaviour and use (e.g. Burnett, 2015; Hassan \& Wolfram, 2019). It has been noted, however, that efforts to analyse cultural factors in detail in such work are limited (e.g. Burke, 2008; Khosrowjerdi et al., 2019). A key weakness is that 'culture' is frequently invoked in the LIS literature as a determinant of information behaviour and use, but without any attempts to unpick the term (e.g. Oh \& Butler, 2019; Shepherd et al., 2018). Indeed, in the body of work accessed for this analysis just three papers include a definition of culture: Caidi \& Allard (2005); Shoham \& Rabinovich (2008); Yeh (2007). Despite this, it is possible to infer definitions through the contextual clues present in the research reported in the papers (e.g., Johnston, 2018; Martzoukou \& Burnett, 2018).

In respect of the information behaviour and use of library patrons, culture is treated in two important ways in this body of literature. First, it allows for distinct user groups to be differentiated (e.g., Khoir et al., 2017; Lloyd, 2017). This is often achieved with reference to values systems connected to culture, including social norms (e.g. Peterson, 2014). The treatment of culture as a differentiator is often used in research on migrant populations to compare new-comer user groups to host country user groups (e.g., Lloyd, 2017). Second, culture is deployed to draw attention to the question of integration (e.g., Johnston, 2018; Lloyd, 2017). An example of this is work by Johnston (2018) in a review of four separate conversation-based public library programmes. The goal of the programmes is to support meaningful interactions between immigrants and members of the host countries, resulting in increased trust and countering segregation (Johnston, 2018 p. 138).

\section{Conclusion}

Despite the inclusion of culture as an influential factor of information behaviour and use, many LIS researchers neglect to define or explore culture as a concept when reporting their research findings. As a result, the concept is deployed inconsistently in the domain.

Appropriate definition of concepts such as 'culture' will help strengthen current and future research on the influences that shape resource use in libraries. In future, researchers should make explicit how such concepts are considered in their research.

\section{References}

Audunson, R., Essmat, S., \& Aabø, S. (2011) Public libraries: a meeting place for immigrant women? Library and Information Science Research, 33, 220 - 227.

Brady, L., Fryberg, S., \& Shoda, Y. (2018). Expanding the interpretive power of psychological science by attending to culture. Proceedings of the National Academy of Sciences of the United States of America, 115(45), 11406-11413.

Burke, S. (2008). Public library resources used by immigrant households. Public Libraries, July/August, $32-41$.

Burnett, G. (2015). Information Worlds and Interpretive Practices: Toward an Integration of Domains. Journal of Information Science Theory and Practice, 3(3), 6-16.

Caidi, N., \& Allard, D. (2005). Social inclusion of newcomers to Canada: an information problem? Library and Information Science Research, 27(3), 302-324.

Hassan, M.D., \& Wolfram, D. (2019). A study of the information behaviors of African refugees. IConference 2019 Proceedings.

Johnston, J. (2018). The use of conversation-based programming in public libraries to support integration in increasingly multiethnic societies. Journal of Librarianship and Information Science., 50(2), 130-140. doi: 10.1177/0961000616631613 
Khoir, S., Du, J., Davison, R., \& Koronios, A. (2017). Contributing to social capital: an investigation of Asian immigrants' use of public library services. Library \& Information Science Research, 39(1), 34-45.

Kitayama, S., \& Uskul, A. (2011). Culture, mind, and the brain: current evidence and future directions. Annual Review of Psychology, 62(1), 419-449.

Khosrowjerdi, M., Sundqvist, A., \& Byström, K. (2020). Cultural patterns of information source use: A global study of 47 countries. Journal of the Association for Information Science and Technology, 71(6), $711-724$.

Lloyd, A. (2017). Researching fractured (information) landscapes. Journal of Documentation, 73(1), 35-47.

Martzoukou K., \& Burnett, S. (2018). Exploring the everyday life information needs and the socio-cultural adaptation barriers of Syrian refugees in Scotland. Journal of Documentation, 74(5), 1104 - 1132. doi: 10.1108/JD-10-2017-0142

Oh, C. \& Butler, B. (2019). Small worlds in a distant land: International newcomer students' local information behaviors in unfamiliar environments. Journal of the Association for Information Science and Technology, 70(10), 1060-1073.

Peterson, K.J. (2014). Including the culturally excluded and socially forgotten: information services for Spanish migrant workers in the United States. Library Quarterly: Information, Community, Policy, 84(3), 390 - 401.

Shepherd, J., Petrillo, L., \& Wilson, A. (2018). Settling in: How newcomers use a public library. Library Management, 39(8/9), 583-596. doi: 10.1108/LM-01-2018-0001

Shoham, S., \& Rabinovich, R. (2008). Public library services to new immigrants in Israel: the case of immigrants from the Former Soviet Union and Ethiopia. The International Information \& Library Review, 40(1), 21-42.

Yeh, N-C. (2007). A framework for understanding culture and its relationship to information behaviour: Taiwanese aborigines' information behaviour. Information Research, 12(2). Retrieved from http://InformationR.net/ir/12-2/paper303.html 